\title{
Mediterranean survey and the city
}

\section{JOHN BINTLIFF \& ANTHONY SNODGRASS*}

The Mediterranean, and especially Greece, provides fine conditions for field-survey - long and intense human occupation, good surface exposure, and distinctive, diagnostic ceramics. Where the Classical authors are conspicuously reticent about the countryside, field-survey can provide a rural picture, as well as the settlement patterns of prehistory. Here, the methods of field-survey return from the countryside to look at the cities, formerly the preserve of the excavator.

What is the city over the mountains

Cracks and reforms and bursts in the violet air Falling towers

Jerusalem Athens Alexandria

T.S. ELIOT, The Waste Land, lines 371-4

The version of archaeological survey which is now being practised in a number of Mediterranean countries - intensive, all-period and aiming at total coverage - has, in the course of its short life, become closely associated with rural landscapes and the rural sector of the economy. These surveys are in part concerned with pre-urban cultures anyway; but there are other reasons why, even for periods after the growth of urbanism, they have avoided major city sites. One of these reasons is the inescapable fact that so many sites of ancient cities in the Mediterranean lands are, if not for ever, at any rate for the duration of our present civilization, inaccessible to survey. Their sites were too well-chosen, and they have remained, or returned to being, major centres of population today. The three cities singled out in the Eliot quotation will serve as examples.

Next, there is the difficulty presented by past excavation, which major city sites have naturally often attracted, and which can be as effective a barrier to survey as modern building is. Only in those cases where the excavations took place some years ago and were subsequently filled in again does this difficulty diminish (as the case of Palaikastro, to be considered below, suggests) to the level of a minor distorting factor.

The third and most controversial set of problems relates to the whole methodology of modern survey. How can procedures adapted to the detection of past activity in the open country, where there is no centre of habitation bigger than the isolated village, be brought to bear on a large urban complex? This is a precise reversal of the original purpose of survey, which was to place excavated urban sites in the context of their rural setting. Are not the cities best left to the excavators who have specialized in them for so long?

\section{Surveying the city: problems and procedures}

At some point in the earlier 1980s, several exponents of intensive survey seem to have decided, quite independently, to answer this last question in the negative. The examples in this paper will be taken from Greece, not through ignorance of what has been achieved elsewhere in the Mediterranean region - at Doganella in Etruria, for instance (Rasmussen 1986: 115-16) - but in order to maintain, as closely as possible, comparability of findings. In cases where an area survey has come unexpectedly upon a large unexcavated site, or where its territory has been deliberately chosen to adjoin one or more such sites, the challenge can hardly be avoided. But means have first to be found of reconciling the results from the rural and urban

* John Bintliff, School of Archaeological Sciences, University of Bradford, Bradford BD7 1DP. Anthony Snodgrass, Department of Classical Archaeology, University of Cambridge, Sidgwick Avenue, Cambridge CB3 9DA. 
sectors. A necessary step, in our view, is to introduce the overall plotting of density of surface finds, to cover the off-site, 'background' areas as well as the rural sites. This step converts the traditional white map with black dots on it into a graded plot, indicating variations in artefact-density all over the landscape. In the Cambridge-Bradford Boeotian Expedition, which we jointly direct, the necessary overall recording was first adopted in our 1980 season, and the mapping carried out during the subsequent winter; our first, primitive density plot was published in 1982 (Snodgrass 1982: figure 2), and full details of our field-walking methods were explained in Bintliff \& Snodgrass (1985). The technique, which we have employed ever since, has been used and indeed refined by others, notably Gallant (1986) in his one-man survey in the Ionian Islands, and the Keos and Nemea Valley surveys (Davis et al. 1985; Cherry et al. 1988). Once the landscape has been graded in this way, an urban site can be set against it, as a zone of very sharply increased density; and other fruitful inferences can then be drawn.

First, though, a massive logistical problem has to be overcome: that of the sheer quantity of finds. Here we digress, for the benefit of nonMediterranean archaeologists who may be wondering why the discussion is being conducted solely in terms of Mediterranean conditions. The explanation lies in the huge differential, relative to what were less developed areas in the ancient world, in the density of surface finds both within and outside the urban sites. Whatever weight be given to the different environmental and historical factors that have played a part in creating this differential (on which see Bintliff \& Snodgrass 1988), the plain fact is that Mediterranean conditions impose altogether different criteria on the field archaeologist from those that he would employ in, say, northern Europe - not to speak of the New World, where the modern survey technique was originally born. This can be seen by looking at T.M. Williamson's application of a closely similar technique to an area of Roman Essex. The sites discovered in his survey are surrounded by a 'halo' of what he terms 'dense concentrations of sherds' (Williamson 1984: 229, figure 2), which means more than 4 sherds per hectare. Such 'haloes' are also familiar in Mediterranean survey; only there they would have to attain about 25 times that density, in order to be classed as such. As for densities within urban sites, in the case of Minoan Palaikastro, to be considered in more detail in a moment, a density of 200 Late Minoan sherds per square metre was recorded at one point in the site (see MacGillivray \& Sackett 1984: 134); and in our own site at Thespiai we have seen this figure locally matched, in the optimum conditions of open, freshly-ploughed land. Clearly, such densities demand a programme of sampling on a large site: even if only one-tenth of this level were maintained throughout, a 10-ha village site would present some two million surface artefacts!

But since most ancient sites are multi-period (Palaikastro is exceptional in this regard), provision must be made for distinguishing the periods, so as to map the city's extent in each of them. This further requirement imposes a further procedure: while sampling is an effective source of overall quantitative information, and a necessary expedient because of the volume of material, it is neither necessary nor effective in bringing out the qualitative distinctions needed for detailed periodization. A small sample from each tract is mathematically unlikely to encompass the full range of material present in that tract. Inevitably, the two different goals lead to two separate operations; and one of these, the unravelling of the periods of occupation, really entails an overall coverage of the ground.

Thus it was that we adopted a two-stage procedure in dealing with these large sites. First, the field-teams covered their entire surface area, using much the same method as in their normal walking in the open country, but with smaller units of terrain to increase precision. We found that a rectangular 'town' transect, $50 \mathrm{~m}$ by $60 \mathrm{~m}$ (that is to say, a $50-\mathrm{m}$ stretch walked by a team of four, spaced at $15-\mathrm{m}$ intervals) gave good results. A density-count of each transect was first taken (using the $5 \mathrm{~m}$ wide strip actually 'seen' by each walker), to give the general indication of where 'site density' was reached, and then a collection was made (over the whole of the $15 \mathrm{~m}$ wide strip). Typically, a transect would yield, out of a very much larger number of sherds and other artefacts, some 20 or so which could be selected on the spot as being clearly diagnostic of the periods of occupation. The team would then examine much more 
intensively a small sample (about $10 \%$ ) of the transect, counting every single artefact and collecting a large number of artefacts. This gave a more precise index of the overall density of occupation, besides sometimes adding to the information on the dates of this occupation. This double procedure was then repeated as often as was necessary to exhaust the area of 'site' density, with allowance made for changes in surface visibility. In the case of the city of Thespiai, 598 such 'town' transects were needed.

\section{The survey of large sites in Greece}

The Boeotia survey has so far encountered three sites of such magnitude as to merit this treatment; by chance rather than by design, we have progressed from the smallest to the largest. The first such site was essentially a new discovery: at the end of our 1981 season, we came on a large site in the Valley of the Muses, which we identified with Askra, the village of the poet Hesiod. Alone of the three, it did not attain the status of an independent polity, but was a kômê within the territory of Thespiai. As such, it had never attracted the attention of an excavator, and belongs indeed to one of the most neglected classes of site in Classical Greece. Its area, when intensively surveyed in 1984, proved to be at least 11 ha. Next, in 1985, we covered the site of Haliartos, a full membercity of the Boeotian League until its destruction by the Romans. Here, two very restricted sectors of the site, one on its acropolis and one in the lower town, had previously been excavated, but their joint area encompassed well under $1 \%$ of the city's area. Acropolis and lower town together covered nearly 30 ha accessible to walking, though there is a possibility that the lower town continued further to the east, under the houses of the modern village that bears its name today. Finally, the site of the more important city of Thespiai occupied us for much of our 1985 and 1986 seasons. Like Haliartos, it had undergone excavations of a limited extent, but it proved to have been far larger, covering well over 100 ha at its maximum period of prosperity.

At this point, it is worth mentioning the work undertaken in the same vein by other expeditions in Greece. The survey of the Minoan town-site of Palaikastro (MacGillivray \& Sackett 1984) has been mentioned already. Carried out in 1983 and promptly published in 1984 , it enjoyed the exceptional advantage that the site had been essentially unoccupied since the end of the Late Bronze Age. Although Palaikastro had had an earlier history of occupation as a site, the urban complex was largely the creation of the Late Bronze Age, and most of the surface pottery belonged to the two main periods of settlement within this time, Late Minoan I and III. Thus the need for one of our two procedures, that of distinguishing the different periods of occupation, was much reduced. This detailed prior knowledge of the site's history resulted from another unusual circumstance: a quite extensive sector of the town had been excavated some 80 years before, and then filled in again. A much larger area was covered by the 1983 survey, incorporating the whole excavated sector, and the presence of the latter does not seem to have created any anomalies in the distribution of surface artefacts, perhaps thanks partly to the intervening lapse of time: the site of the excavation lay within a larger central zone of maximum density. The surface survey was followed up by a series of magnetometer tests, again recalling a practice of ours in Boeotia, except that we have preferred to use the electric resistivity meter; while others have used one or other of these instruments as a primary method of investigating an urban site with notable success, as at Stymphalos near Corinth where the resistivity meter was also remarkably effective (Williams 1985). At Palaikastro, by contrast, the magnetometer results were disappointing; the method was perhaps inappropriate to such a highly urbanized site.

The Palaikastro operation provides a useful illustration of the handling of an essentially one-period urban site by means of survey. A much closer analogy to our work, however, was offered (unknown to either party) by the operations of the Keos Survey in the same year, 1983. Its survey territory included not only two known sites of the later Neolithic, hardly to be classed as 'urban', but also the Classical polis of Koressia, comparable in status with our site of Haliartos. The main difference was the much greater prevalence, as often in the Cyclades, of partly standing walls, particularly the defensive ones on the acropolis of Koressia. The surface of the site was treated in a single operation, with transects of $50 \mathrm{~m}$ by $25 \mathrm{~m}$, with some supplementary investigation. Something over 40 ha 
were covered at the same level of intensity, though the maximum extent of the true inhabited area was ultimately judged to have been much less, not exceeding 6-8 ha (Davis et al. 1985: 113 and, much more fully, Whitelaw \& Davis, forthcoming). Several of the participants in the Keos project moved on, in 1984 and following seasons, to join in the direction of the Nemea Valley Archaeological Project in the northeast Peloponnese. Here they were to encounter the much larger polis site of Phlious, a match for our site at Thespiai. Sporadic excavation of this more than 100-ha site had taken place in earlier years. Coverage of the greater part of the city was achieved by a section of the Nemea team in the 1986 season, and it awaits further work before final publication: again, we are most grateful to Susan E. Alcock and the Directors for much preliminary information.

Finally, even as we write, the Laconia Survey further south in the Peloponnese is working on two large sites which lie within its territory: the town at Chrysapha and the prehistoric settlement and Classical sanctuary on the Menelaion hill. Other expeditions have followed the more traditional, and equally valuable, pattern of associating the excavation of an important settlement with the survey of its surrounding territory. Notable examples are the pioneer project of the 1960s, the University of Minnesota Messenia Expedition, with its excavation at Nichoria (see most recently McDonald et al. 1983); and a second American undertaking in Greece, the Argolid Exploration Project, which excavated the Classical city site of Halieis, in addition to its famous prehistoric investigation of the Franchthi Cave (see most recently van Andel \& Runnels 1987).

\section{Three examples from Boeotia}

So, in the short space of the last four or five years, intensive survey of historical city sites in the Aegean area has suddenly 'arrived' as a primary medium for archaeological research. We shall close with an attempt to justify this development; but first, something should be said about the specific part played in it by our work on the three Boeotian sites. Our survey is almost entirely located on what is, by Greek standards, prime agricultural land. The intensity of modern agriculture probably explains why such high off-site densities occur in Boeo- tia, and why such phenomena as the 'halo' surrounding a site are present there in so conspicuous a form. The same factor affects the interpretation of the city sites. With the inevitable expansion and shrinkage of major settlements from period to period, terrain which, when the site was small, formed part of the 'halo' around the actual area of habitation, will have been swallowed up in this occupation area at times when the site was larger. When estimating the size of the inhabited area at a given period, therefore, one must impose a fairly demanding criterion of density of material of that period, before designating a locality as having been then inhabited. A few diagnostic sherds in a transect may well reflect in-field cultivation rather than occupation.

\section{Askra}

With Askra, for example, we have a history of settlement that shows discontinuity, fluctuations in the size of the built-up area, and a more gradual shift in the location of the nucleus
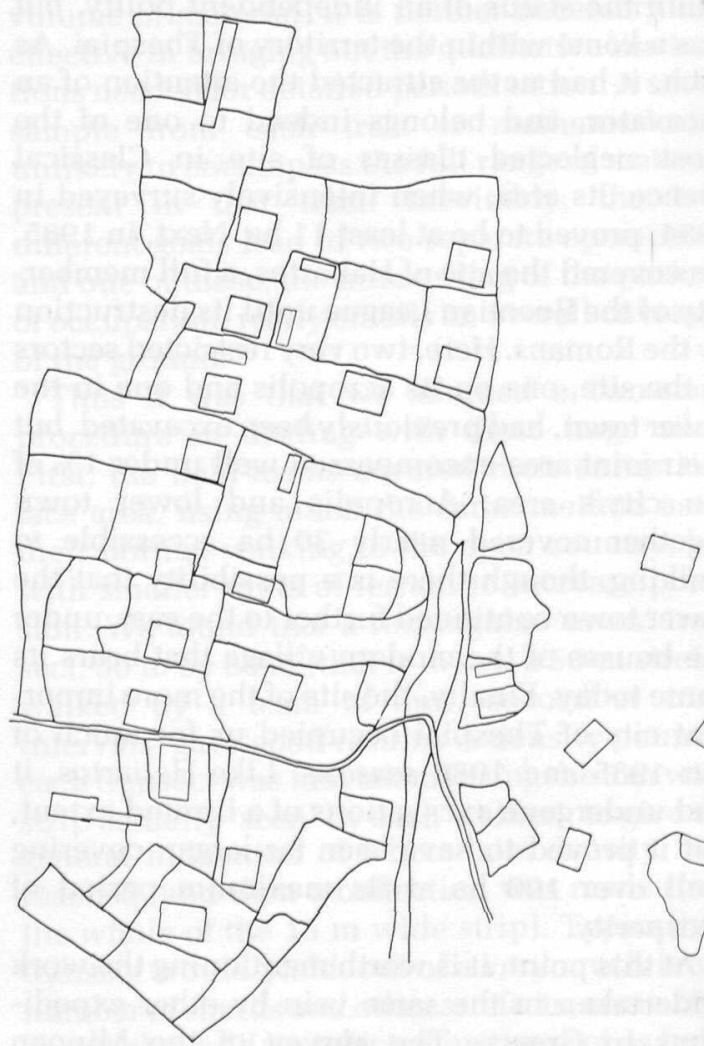

FigURE 1. Askra: the modern field-boundaries. Rectilinear symbols show locations of samples. 
of the site. We would claim that intensive overall survey is the only method, short of total excavation of the site, which could detect all three of these dimensions of change. The site of ancient Askra is criss-crossed by substantial modern stone walls (FIGURE 1), which act as field-boundaries. We therefore chose to use these modern fields as the units for survey, rather than imposing a rectilinear grid on the site; the intensive samples were later located within these units. The imparity of size of the units made the density calculations more complicated, but did not vitiate the results. Only when the entire site had been covered did a coherent history of occupation emerge (FIGURES 2a-e). There had been an area of prehistoric settlement dating to the Early Bronze Age, but it was so narrowly concentrated towards the northwest extremity of the site (centred on the dark-shaded areas of Geometric settlement in FIGURE 2a) that in 1982, when we carried out field-walking all round the settlement but only sampled its interior, we missed this episode altogether. But even total coverage in 1984 failed to reveal any material whatever from the ensuing thousand years or so (including the whole Mycenaean age), and we must infer that the site was deserted, probably in favour of the neighbouring hill-top to the west, Pyrgaki, which has produced Late Bronze Age material, and which was later to act as an acropolis for the reoccupied settlement below.

It was in the Early Iron Age that people returned to the site of Askra, leaving their traces in pottery of the 9th and 8th centuries BC. Interestingly, their main occupation-area (shaded dark in FIGURE 2a) lay precisely within the abandoned Early Bronze Age settlement, suggesting that house-ruins may have survived the intervening millennium. This later period covers the lifetime of Hesiod, who writes of Askra as his home; so that, assuming the correct identification of the site (Snodgrass 1985), we can give his poems a topographical setting. In the ensuing centuries, Askra grew slowly and, like most of our settlements, reached its maximum size in about the 4th century BC (FIGURE $2 \mathrm{~b})$. Then decline sets in, and there is a conspicuous dearth of material of earlier Roman Imperial times. This last point is also important for our identification of the site, because in the 2nd century $\mathrm{AD}$ the travel-writer Pausanias states that, in his day at Askra, there was "a tower and nothing else to remember it by' (ix 29, 1). The 'tower' mentioned by him is undoubtedly the Late Classical one that still surmounts, and gives its name to, the Pyrgaki hill immediately to the west. Before this period of desertion Askra had already begun to shrink and as it did so, in Hellenistic times, the main nucleus of settlement had begun to shift southwards (FIGURE 2c). This shift was maintained in the remarkable revival of the 4 th to 6 th centuries AD (FIGURE 2d), when Askra recovered its former size. The Early Byzantine age sees another interval of probable abandonment; but there is a final reoccupation covering Late Byzantine and Frankish times, which ended with the final desertion fairly early in the period of Turkish rule (FIGURE 2e). By then, the settlement at Askra no longer had any physical overlap with its first originator, the Early Bronze Age site.

An all-period survey, however, must pay attention to developments through time and space right down to the present day. So it is important to add that the final abandonment of Askra was apparently occasioned by the choice of a new location for the main settlement in the Valley of the Muses. This site (our 'Valley of the Muses 4') lies on the hill-slope to the east of Askra; it had already seen lengthy periods of occupation, but its most copious material is of the Turkish period, and indeed it was noted by at least one of the early travellers to Greece, in the 17th century, before it too met with desertion, in favour of the site of the modern village at the mouth of the valley, universally known as 'Panagia' except to officialdom, which has bequeathed it the name of 'Askraia'. These and other comparatively recent shifts of settlement are charted in FIGURE 10, which correlates them with the extent of the prime agricultural soils in our area. This illustrates a kind of long-range 'horizontal stratigraphy', on a regional scale, that intensive survey is uniquely adapted to reconstruct, with the aid of a little surviving documentation.

\section{Haliartos}

Haliartos, our second site, was in some ways a more straightforward proposition, physically and historically. With a firm if minor place in the ancient documentation, its site had long since been identified through the partial survival both of its city-walls and of the smaller 

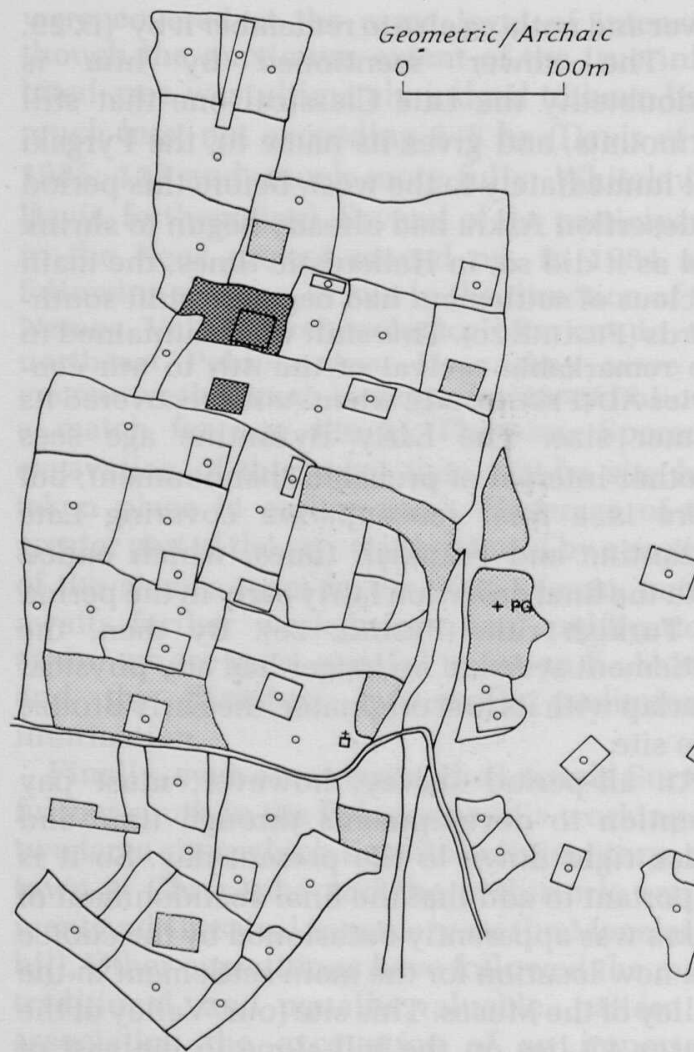

Figure 2a. Askra: Geometric and Archaic periods.

Transects and samples with moderate (darker shaded) or low (lighter shaded) density of finds of these periods. Transects marked with a zero are known to have produced none.

circuit which enclosed its acropolis, on the highest ground at the northern extremity of the city. What is more, it lies on fallow land covered by thin grass, without internal barriers, just west of the modern village (FIGURE 3). A grid of rectangular transects, $50 \mathrm{~m}$ by $60 \mathrm{~m}$, could thus be laid across the entire accessible area of the city, and the samples located within these (FIGURE 4). The results, too, conformed to a recurrent pattern of Greek city-sites. As in many cities with a Bronze Age forerunner, the-prehistoric site was located entirely within the area of what was later to become the acropolis. This early settlement lasted through all three phases of the Bronze Age, and was then succeeded by a phase of apparent desertion that is echoed in many major settlements, even extensively excavated ones. Classical Haliartos, which fills most

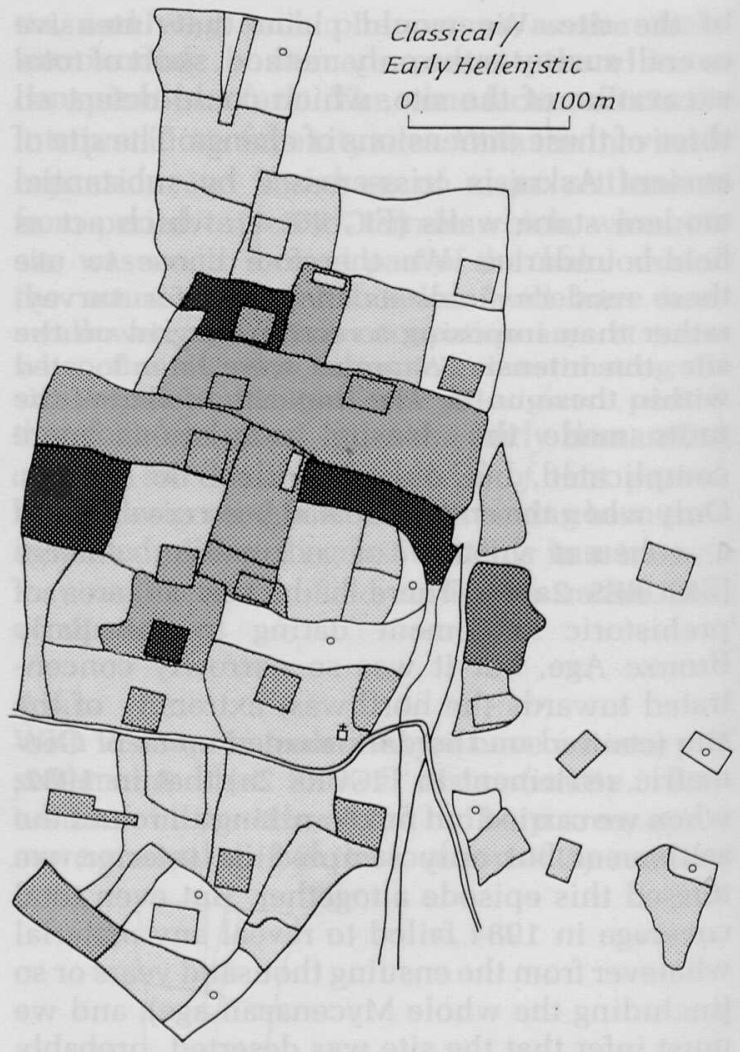

Figure 2b. Askra: Classical and Early Hellenistic periods.

Transects and samples with high (dark), moderate (medium) and low (light-shaded) density of finds of these periods. Transects marked with a zero are known to have produced none.

of the space within its contemporary town walls, had its origins in an Early Iron Age settlement that was, like Askra's, at first located within the former prehistoric area of occupation (FIGURE 5a: 'Geometric'). From this nucleus on the highest ground, it spread gradually down the slope to the south (FIGURE 5a, 5b). The distinctive event in this site's history was its destruction and devastation by the Romans in $171 \mathrm{BC}$, for having taken the wrong side in their war with Perseus of Macedon. This event was heavily underlined by the results of the survey, for the pottery-series breaks off in the course of the Hellenistic period and never properly resumes. Only two areas of later activity were found: some (mainly late) Roman material encroaches on to the south-eastern quarter of the accessible part of the site (FIGURE 5c); and a 

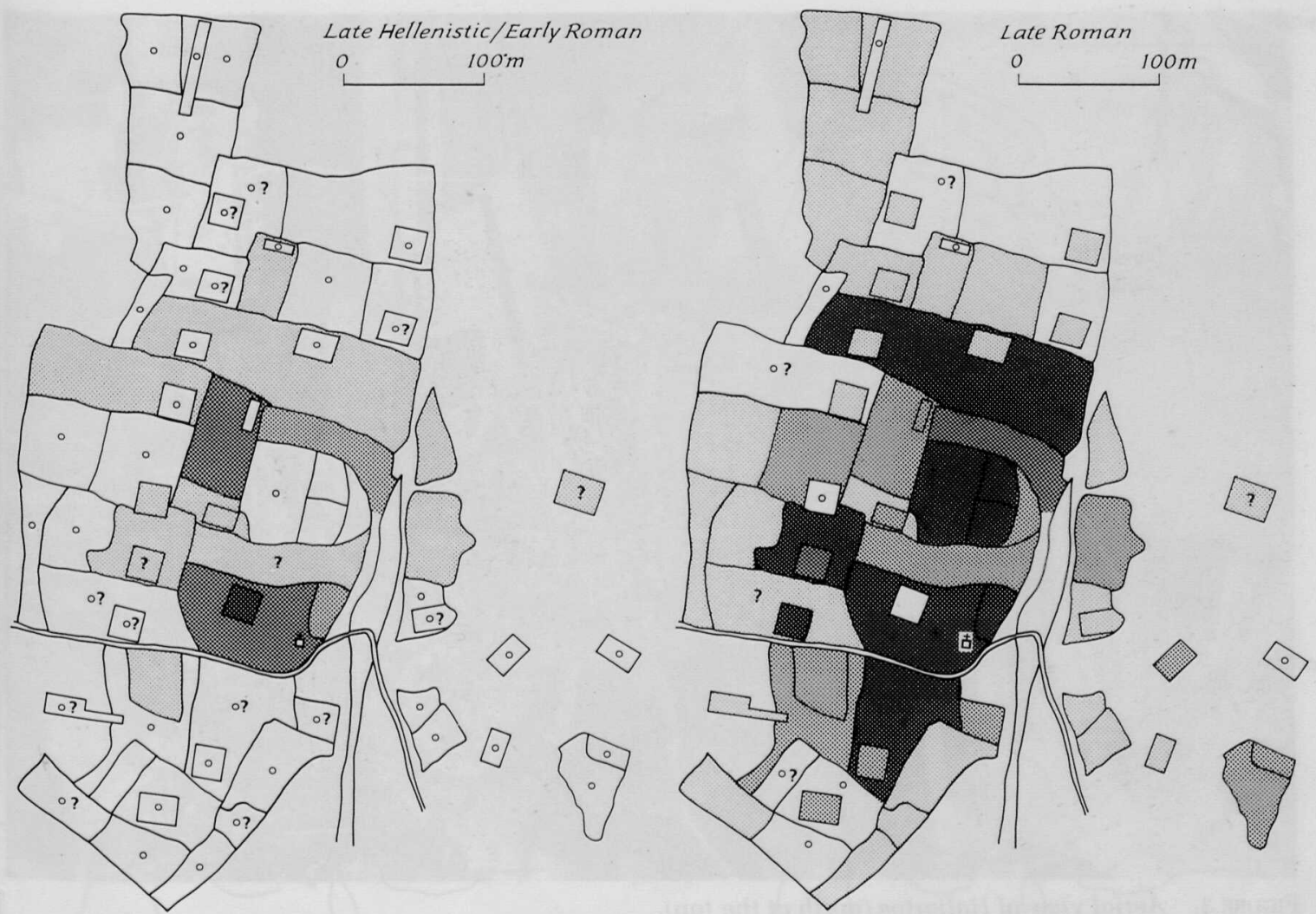

FIGURE 2c. Askra: later Hellenistic and earlier Roman periods.

Transects and samples with high (dark), moderate (medium) and low (light-shaded) density of finds of these periods. Transects marked with a zero are known to have produced none.

FIGURE 2d. (top right) Askra: Late Roman period.

Transects and samples with high (dark), moderate (medium) and low (light-shaded) density of finds of this period. Transects marked with a zero are known to have produced none.

FIgure 2e. Askra: Byzantine to Turkish periods. Locations of finds of these periods.

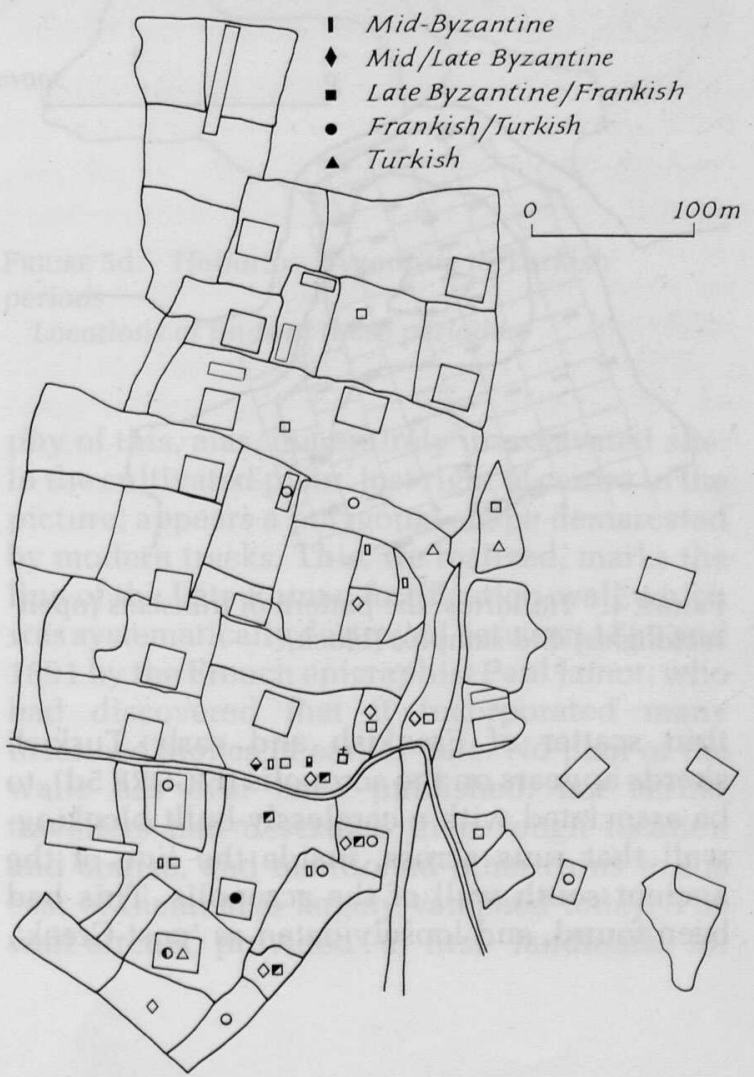




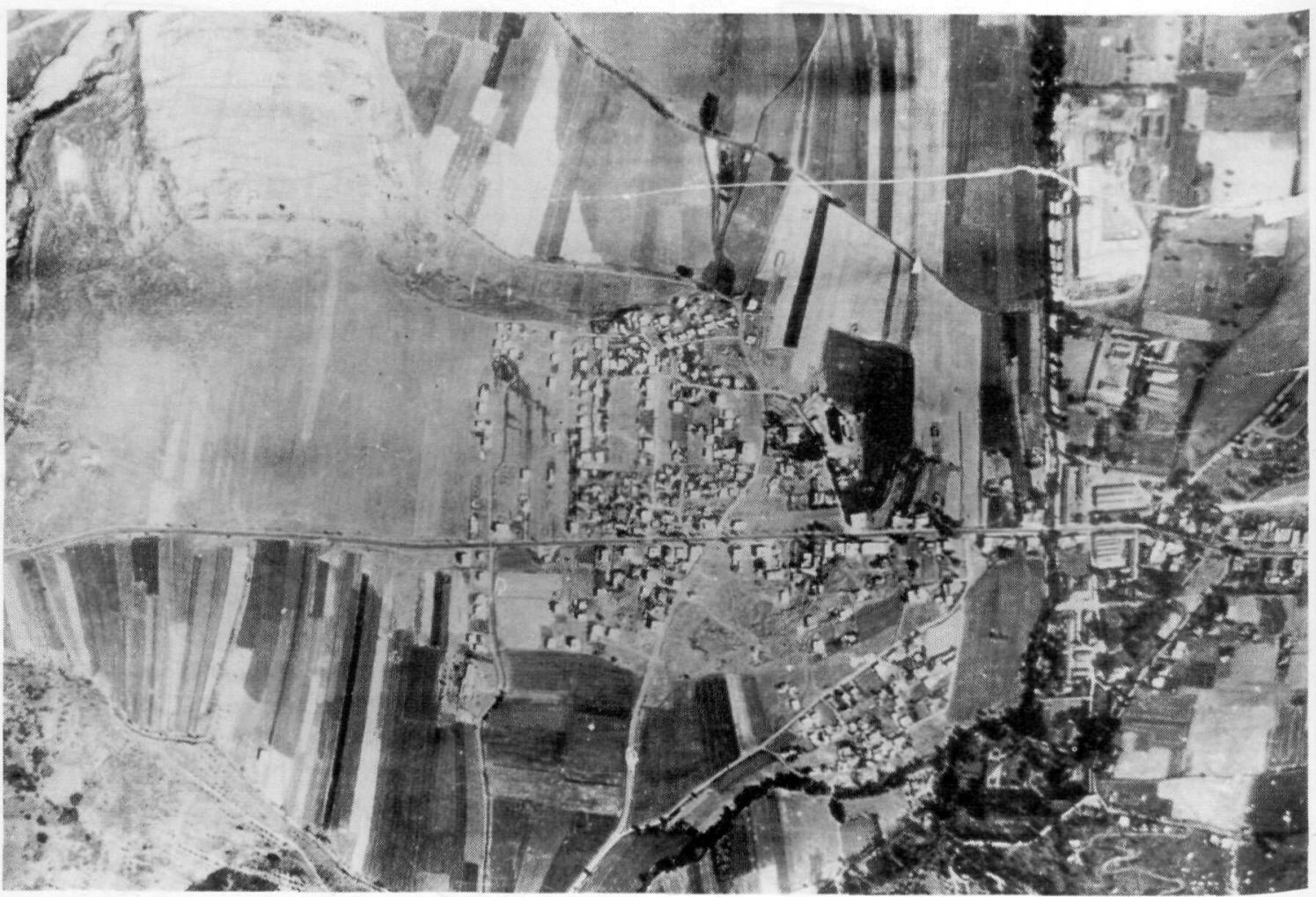

FIGURE 3. Aerial view of Haliartos (north at the top).

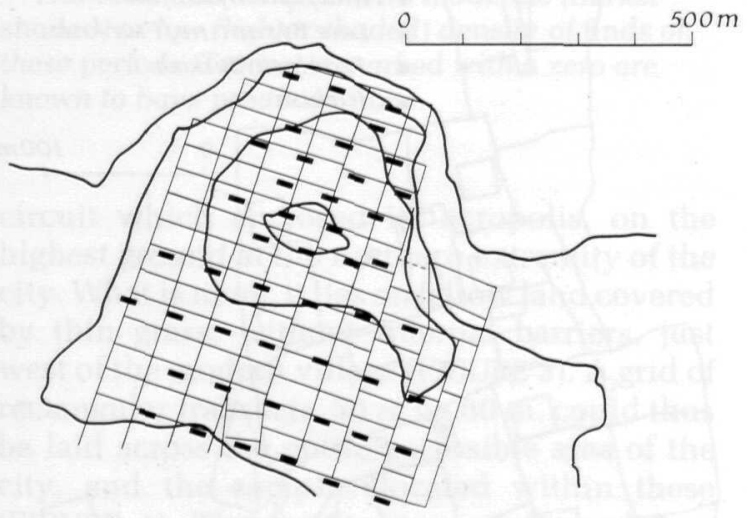

FIGURE 4. Haliartos: the pattern of transects lopen rectangles) and samples (black).

thin scatter of Frankish and early Turkish sherds appears on the acropolis (FIGURE $5 \mathrm{~d}$ ), to be associated with a carelessly-built blockingwall that runs across, inside the line of the ancient'south wall of the acropolis. This had been found, and loosely dated as 'post-Greek', by R.P. Austin during his excavation of 60 years earlier (Austin 1926: 82, 86).

With Haliartos, too, a sequence of later sitelocations can be reconstructed. While the final, late medieval reoccupation of the old acropolis was taking place, a new settlement had grown up a few hundred metres to the southeast. Here there were extensive architectural traces still visible last century, where they were noted by some of the later travellers, including the incomparable Colonel Leake, who reported the ruins of both churches and a mosque (in 1986-7 we initiated study of the abundant surface material from this locality, predominantly 12th-16th century AD in date). By then, however, the bulk of the population had moved again, to the modern village called Mazi, a mile or two to the southwest on the lower slopes of Mt Helikon; and from there they descended only in the 20th century, as a consequence of the growth of the British Lake Copais Company which was engaged in draining the near-by lake basin, to the present-day village of Haliar- 


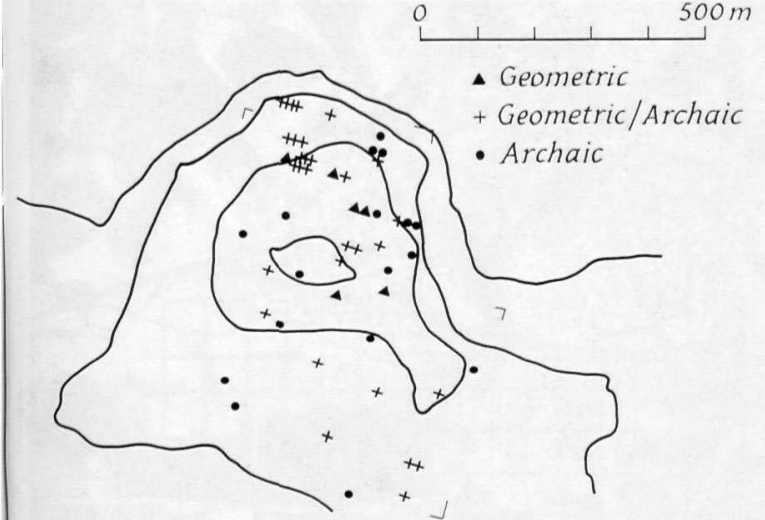

FIGURE 5a. Haliartos: Geometric and Archaic periods.

Locations of finds of these periods.

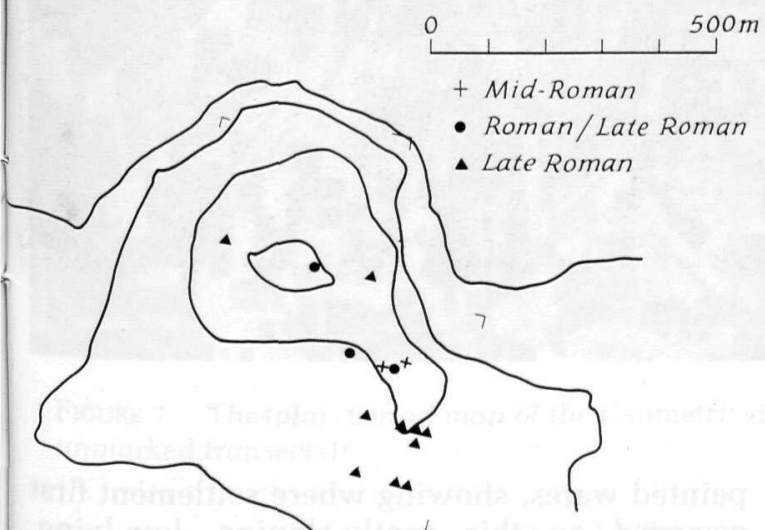

FIGURE 5c. Haliartos: Roman period. Locations of finds of this period.

tos. These shifts are again indicated on FIGURE 10.

\section{Thespiai}

The third and largest site, Thespiai, tested us to the limit, and there were moments when we asked ourselves whether it was worth our perseverance in surveying it at the same level of intensity. As befitted a city with an extensive territory and a leading, often independent role in Boeotian history, Thespiai proved to be on a metropolitan scale. The aerial photograph (FIGURE 6) shows the feature that provided our first break-through in unravelling the topogra-

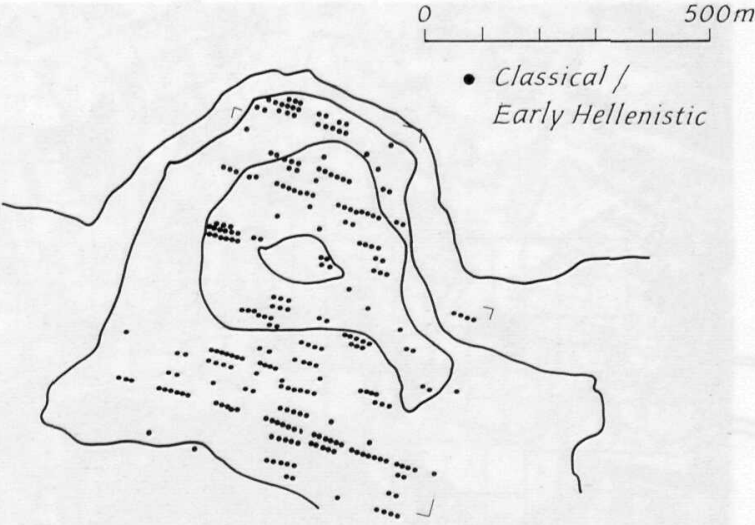

Figure 5b. Haliartos: Classical and Early Hellenistic periods.

Locations of finds of these periods.

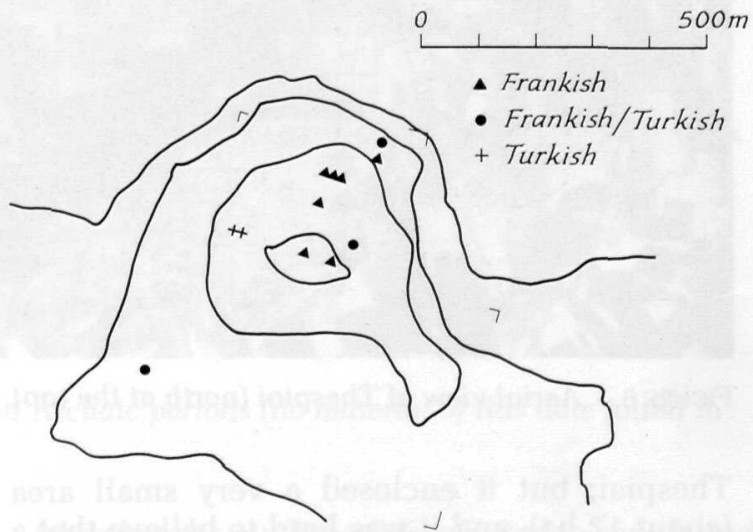

FIGURE 5d. Haliartos: Byzantine to Turkish periods.

Locations of finds of these periods.

phy of this, alas, not entirely unexcavated site. In the cultivated plain, just right of centre in the picture, appears a polygonal shape demarcated by modern tracks. This, we realized, marks the line of the Late Roman fortification-wall which was systematically destroyed between 1889 and 1891 by the French epigraphist Paul Jamot, who had discovered that it incorporated many inscribed stones of earlier date. No plan of the walls has ever been published; but earlier travellers had described their rough location and course, and mentioned other ruins to the east of them, also largely vanished today. The wall-circuit provided a first landmark for 


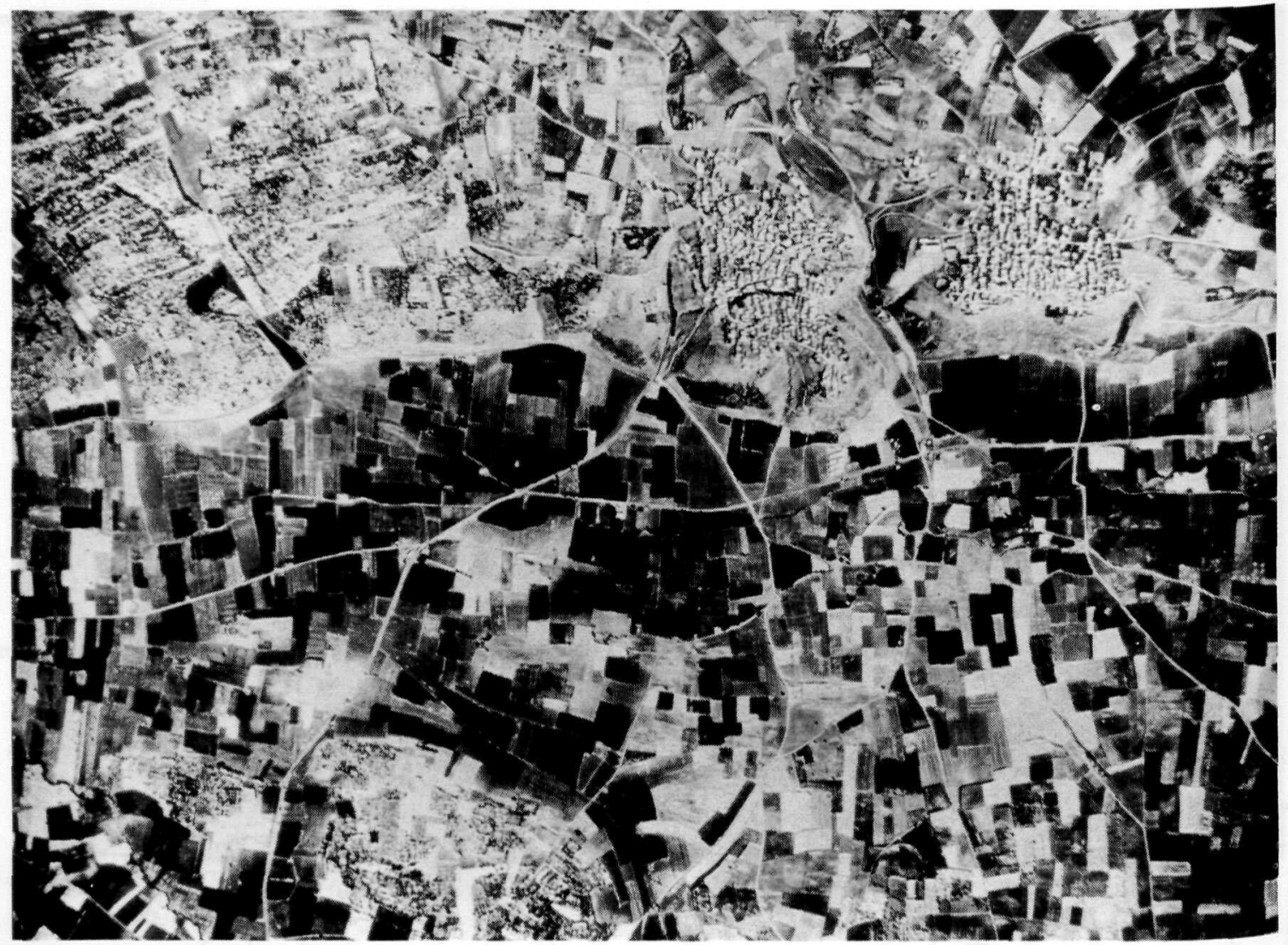

Figure 6. Aerial view of Thespiai (north at the top).

Thespiai; but it enclosed a very small area (about $12 \mathrm{ha}$ ), and it was hard to believe that a famous and prosperous city had been entirely, or even largely, confined within these limits. Were the 'ruins' to the east a clue to the answer?

The laborious investigation of the site showed otherwise. Because of the quantity and density of the surface material, we were able to prepare detailed period maps of Thespiai at each main phase of its occupation from the Neolithic to the Ottoman period. FIGURES 7-9 show three of the most revealing of these period maps; but it will be easiest to follow again a chronological sequence in reconstructing the development of the site. First, Thespiai enjoys some repute as a rich source of Neolithic surface-finds (Caskey 1951). A short way to the northeast of the polygonal enclosure, the ground, rises slightly to form a magoula or artificial elevation: here, and only here, we found a thick concentration of fine Neolithic painted wares, showing where settlement first occurred on this gently-sloping, low-lying, well-watered site. Thereafter, Thespiai expanded; but throughout the Bronze Age, and on into the Early Iron Age and even the Archaic period, occupation material presents a curiously sporadic pattern, as if there were not one but several small nuclei of settlement. For the later period at least (9th to 6th centuries BC: FIGURE 7), this picture conforms to the model for the growth of the historical Greek city from a scatter of separate villages or hamlets, for which the classic illustration - since it is described in such terms by Thucydides (i 10, 1) in the 5th century BC - is ancient Sparta. A straggling, unwalled Thespiai cannot however have lasted indefinitely, for we learn from the same writer (iv 133, 1) that by the 5 th century the city was fortified. The Classical period map (FIGURE 8) shows a huge spread of material: it includes an extension to the north of the Thespios river, which provides the nearest 


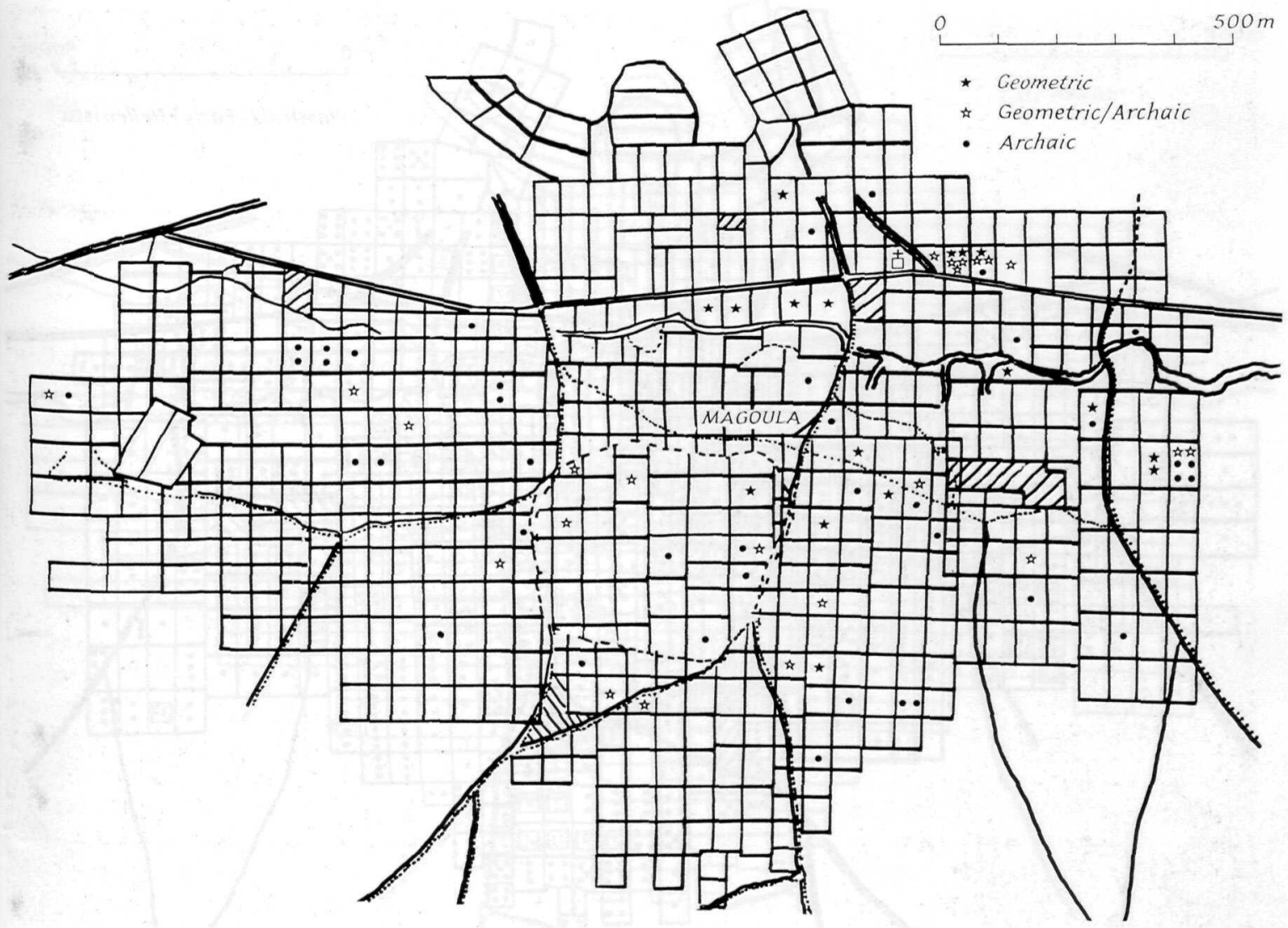

FIgurE 7. Thespiai: period map of the Geometric and Archaic periods (no material of this date found in unmarked transects).

thing to a natural boundary on this side of the site; while its main extent is to the west, not as predicted to the east, of the polygonal enclosure. As for the Classical city-wall, it was only in 1987 that, by a chance observation, the first clue emerged as to its location. Exceptionally deep ploughing brought to light a line of three huge squared blocks, each well over a metre in length and nearly as broad, which can only have been defensive in purpose. They lay in a field immediately to the north of the Neolithic magoula, and they ran approximately east-west. If this marks the line of the northern city-wall, then it would suggest a walled area very much larger than the Late Roman polygon, yet still not extensive enough to enclose all the areas of high Classical density, some of which - including the sector beyond the river - must have been extramural. There is another, negative indication of the extent of the walled city, in that an excavation of 1981 (shortly to be published) is reported to have found graves of the Archaic and Hellenistic periods at a point just inside the eastern wall of the polygon. Since the Greeks habitually located their cemeteries outside the walls, this suggests that, at least in these two periods (though perhaps not at the time when the city's north wall ran across to the point shown in FIGURE 8), this spot lay outside the then east wall. Certainly this find underlines the discontinuity between the Classical and the Late Roman fortifications, and the area within the Late Roman polygon was in general by no means especially rich in Classical material.

With the Late Roman map (FIGURE 9), the elements at last fall clearly into place. Out of 31 transects with more than six diagnostic Late Roman sherds, no less than 23 lie within the polygonal enclosure, confirming this as the main nucleus of the city in late antiquity. The 


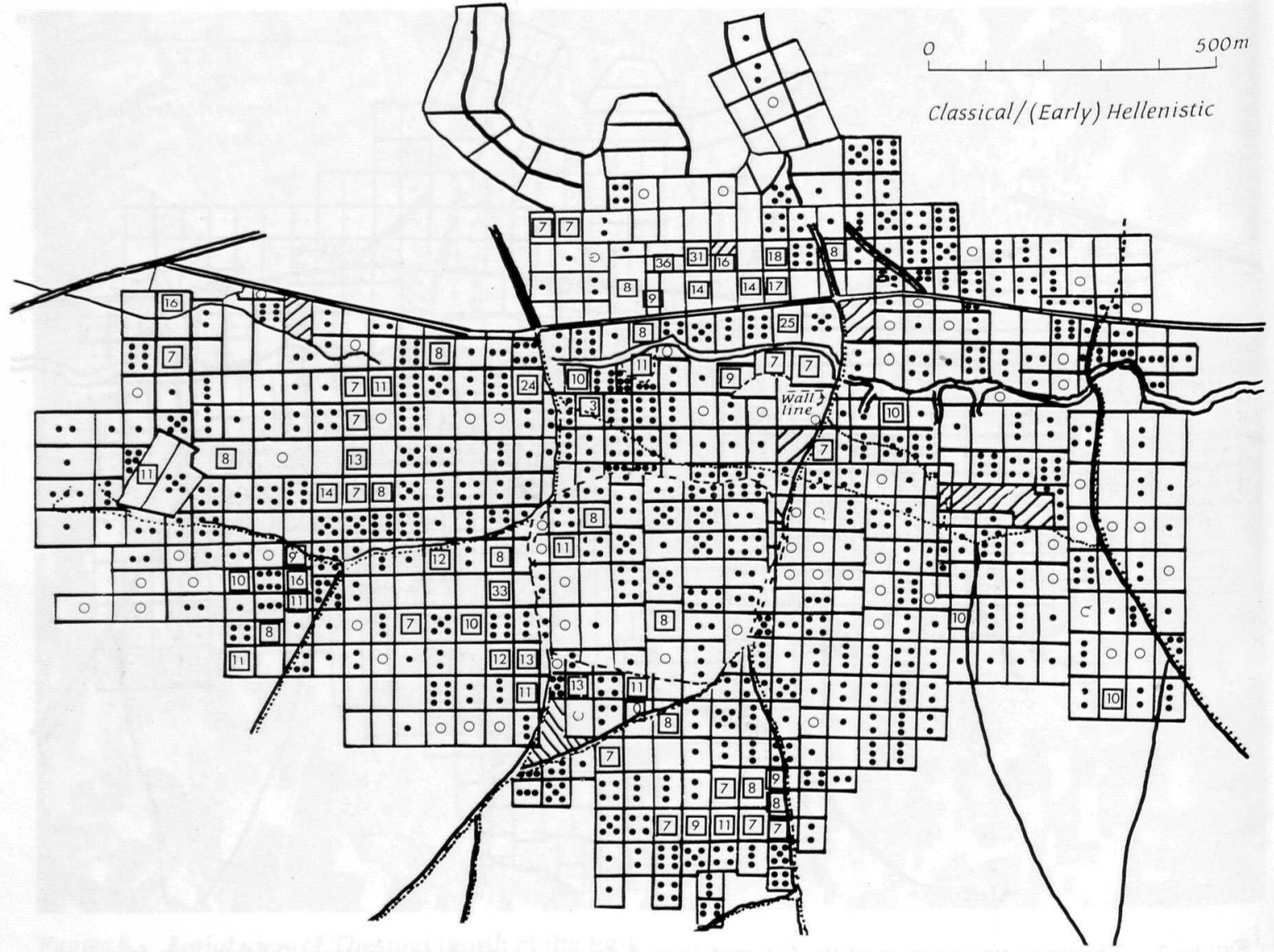

FIGURE 8. Thespiai: period map of the Classical and Early Hellenistic periods.

Transects with more than six finds of this date are marked with a numeral; those known to have produced none are marked with a zero; those left blank were inaccessible, or outside the city area.

remaining high-density areas lie, for the first time, predominantly to the east; and this tendency is continued in the Byzantine era, which is further attested by the scanty remains of at least four churches in this locality. Thus we have the explanation for the travellers' observations: the latest phase in the city's life, with the most substantial surviving structures, was indeed concentrated to the east of the enclosure; but this had come about, unknown to them, through the gradual displacement of the settlement eastwards. The last surviving hamlet on the site, in this same eastern sector, was indeed only abandoned between two visits of Colonel Leake, in 1802 and 1806. By then, most of the population had already moved elsewhere: there is a substantial site of mid-Turkish date (our 'PP 23') a short distance to the west, and there is also the present- day village to the north, which existed for some centuries under the name of Erimokastro before being officially re-named Thespiai. The ancient site then reverted entirely to the open agricultural land that is the heart's desire of the surface investigator.

\section{Discussion}

It remains to say a few words in justification of the expenditure in money, time and labour that the survey of these three sites represents. A first point is that this expenditure, in the conditions of contemporary Greece, would not have sufficed for an excavation of more than two or three $5-m$ trenches in each of our three sites. Would we have been better occupied in this latter activity, restricted though it might be? Some would undoubtedly say that we would, and 


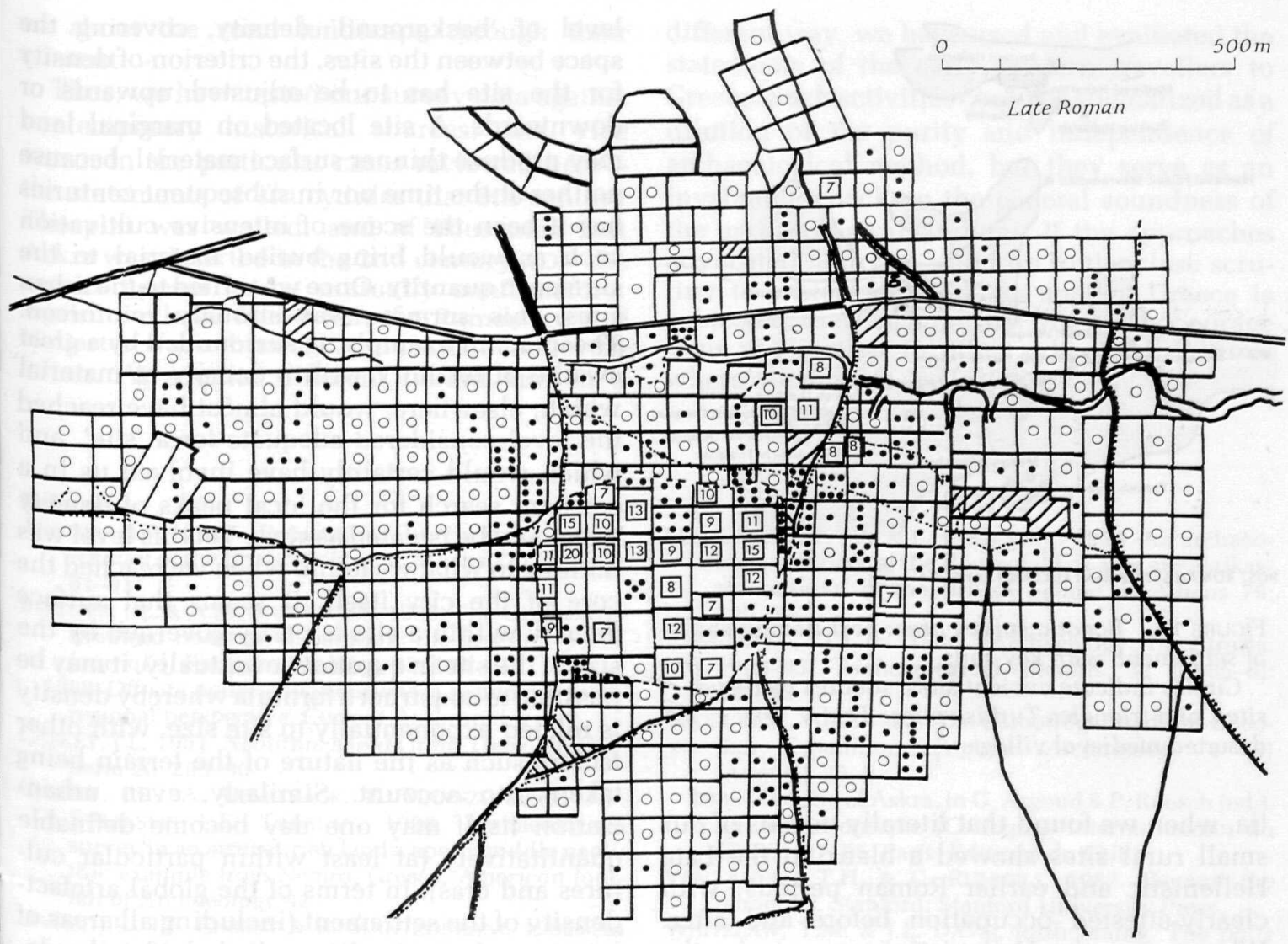

Figure 9. Thespiai: period map of the Late Roman period.

Transects with more than six finds of this date are marked with a numeral; those known to have produced none are marked with a zero; those left blank were inaccessible, or outside the city area.

indeed there are times when one asks oneself whether the 'cities' that we have put on the map have any greater substance than those of The Waste Land, 'cracking, reforming and bursting'. But the method must be judged by its potential, rather than by its early and experimental attainments; and if we are right in our conviction, this method will be carried to far greater refinement by future archaeologists in Greece and elsewhere.

The first justification for incorporating citysites in an intensive survey is that, without them, the picture of the rural landscape will be seriously incomplete. Again and again with rural surveys, a phenomenon of cyclical dispersion and contraction has been noted: one period will see the occupation of a wide scatter of outlying sites, the next their abandonment. But is this abandonment a sign of falling population and neglect of agriculture, or does it merely mean that nucleation has come into favour, with the population concentrated in the nearest town? Only the investigation of the town-sites of the same period will give the answer. When, as at the end of the Bronze Age, in the Hellenistic and earlier Roman periods, or in Early Byzantine times in Boeotia, there is shrinkage or desertion both in the larger settlements and in the small outlying ones, then nucleation is clearly inadequate as an explanation.

Urban sites operate to similar effect with the problems of periodization. On a small site, with its much more restricted yield of surface material, one may have serious misgivings as to whether a 'missing' period really indicates that the site was abandoned at that time - particularly if it shows signs of eventual reoccupation later. This very question confronted us in Boeo- 


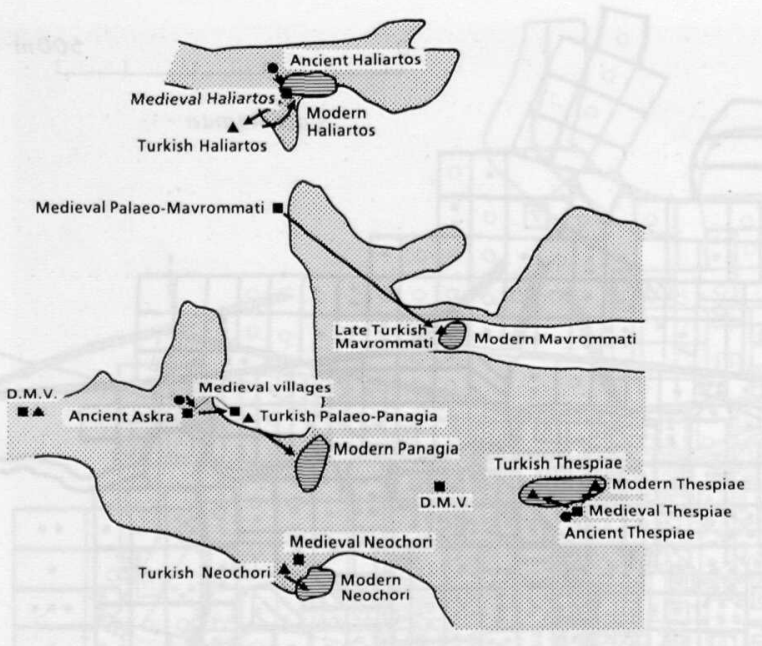

POST ROMAN SETTLEMENT FOCI AND KEY SOILS

FIGURE 10. Boeotia survey area: post-Roman shifts of settlement, with key soils.

Circles indicate ancient sites, squares medieval sites, and triangles Turkish sites. 'D.M.V' = deserted medieval village.

tia, when we found that literally dozens of our small rural sites showed a blank in the Late Hellenistic and earlier Roman periods, with clearly-attested occupation before and after. Where were the Hellenistic unguentaria, the Arretine and Samian wares, or even the early Imperial coarse amphorae? Could Boeotia have been a region little involved in the import or imitation of the well-known diagnostic wares for this period? Was it possible that we were looking for the wrong things, and failing to recognize contemporary local fabrics? Here it was reassuring to find, in the cities and towns, solid assemblages of all these classes of pottery, together with other wares not previously encountered in the small sites. This at least went some way towards indicating that the gap in the occupation of the latter had been a real one.

Next, there is an argument of a more technical kind, which nevertheless seems to us worth stating. It relates to the density of surface material. Seekers after scientific objectivity have naturally wished to establish an absolute criterion of density that can be used to define a 'site', wherever it may lie. Our experience had already suggested to us that such standards could only be relative ones: depending on the level of 'background' density, covering the space between the sites, the criterion of density for the site has to be adjusted upwards or downwards. A site located on marginal land may produce thinner surface material, because neither at the time nor in subsequent centuries has it been the scene of intensive cultivation such as would bring buried material to the surface in quantity. Once we turned to the urban sites, this surmise was strongly reinforced. Thespiai, for example, is surrounded by a great swathe of territory with a density of material which, elsewhere, would almost have reached the level considered adequate for a 'site', and which would certainly have involved us in a constant search for the local peaks of density that could be isolated as sites. Yet this level was nothing to what we found when we reached the core of the city itself. It seems that surface density within a site is partly governed by the size of the site in question: eventually, it may be possible to construct a formula whereby density is related exponentially to site size, with other factors such as the nature of the terrain being taken into account. Similarly, even urbanization itself may one day become definable quantitatively (at least within particular cultures and eras), in terms of the global artefactdensity of the settlement (including all areas of intra-mural waste disposal), calculated relatively to that of the immediately adjacent landscape.

The final justification is one that may appeal only to historical archaeologists. It is a constant aim of those of us who work in historicallydocumented periods to test our findings against contemporary written sources. Contrary to widespread belief among other archaeologists, we do not always do this in a spirit of deference: the results may indeed confirm, but may also supplement or contradict the written sources. Many kinds of resolution and reconciliation are possible, and they can be salutary both for history and for archaeology. But in the case of ancient Greece, because of the general neglect of the rural landscape by the Classical authors. such testing and confrontation is, on a specific level, normally only possible with the larger urban sites, since they alone merited particular mention in the sources. Even inscriptions, though their find-spots may prove informative in cases where one can be sure that they are more or less in situ, only occasionally enlighten 
us about the rural landscape through their content.

Thus, we have tested our survey data against contemporary historical sources, and vice versa. In the particular cases reviewed here the statements of Thucydides that 5th-century Thespiai was walled, and of Pausanias that Askra was deserted in the 2nd century AD - the results appear to be mutually confirmatory. Again, we have found that the Roman sack of Haliartos was a thorough and permanent devastation. At a quite different period and in a

\section{References}

Austin, R.P. 1926. Excavations at Haliartos, 1926, Annual of the British School at Athens 27 (1925-6): 81-91.

BinTLIFF, J.L. \& A.M. SNODGRASS. 1985. The Cambridge/ Bradford Boeotian Expedition: the first four years, Journal of Field Archaeology 12: 123-61.

1988. Off-site pottery distributions: a regional \& interregional perspective, Current Anthropology 29.

CASKEY, J.L. 1951. Neolithic sherds from Thespiai, Hesperia 20: 289-90.

Cherry, J.F., A. DEMITRACK, E. Mantzourani, T.F. STRASSER, L.E. TALALAY. 1988. Archaeological survey in an artifact-rich landscape: a middle neolithic example from Nemea, Greece, American Journal of Archaeology 92.

Davis, J.L., J.F. ChERry \& E. MANTZOURANI. 1985. An archaeological survey of the Greek island of Keos, National Geographic Society Research Reports 21: 109-16.

GALlanT, T.W. 1986. 'Background noise' and site definition: a contribution to survey methodology, Journal of Field Archaeology 13: 403-18.

MCDONALD, W.A., W.D.E. COULSON \& J. ROSSER. 1983. Excavations at Nichoria in Southwest Greece 3. Minneapolis: University of Minnesota Press. different way, we have used and evaluated the statements of the early modern travellers to Greece. Such activities could be stigmatized as a dilution of the purity and independence of archaeological method, but they serve as an invaluable check on the general soundness of the archaeological findings. If the approaches advocated here can stand up to the close scrutiny to which all work on ancient Greece is subjected, then we hope that this will encourage their application to other urbanized cultures where documents are lacking.

MACGILlivray, J.A. \& L.H. SACKETT. 1984. An archaeological survey of the Roussolakkos area at Palaikastro, Annual of the British School at Athens 79: 129-59.

RASMUSSEN, T.L.B. 1986. Archaeology in Etruria, 1980-85, Archaeological Reports 32 (1985-6): 102-22.

SNODGRASS, A.M. 1982. The Cambridge/Bradford Boeotian Expedition, Popular Archaeology 4 (2) (August): 36-9.

1985. The site of Askra, in G. Argoud \& P. Roesch (ed.), La Béotie antique (Colloques internationaux du CNRS): 87-95. Paris: Éditions du CNRS.

VAN ANDEL, T.H. \& C. RunNELS. 1987. Beyond the acropolis. Stanford: Stanford University Press.

WhITELAW, T.M. \& J.L. DAVIS, forthcoming. The polis centre of Koressos, in J.F. Cherry, J.L. Davis \& E. Mantzourani, The archaeological landscape of northern Keos.

WILliams, H. 1985. Investigations at Stymphalos, 1984, Classical Views (Echos du Monde Classique) 29 (n.s. 4): 215-24.

WILLIAMSON, T.M. 1984. The Roman countryside: settlement and agriculture in NW Essex, Britannia 15: 225-30. 